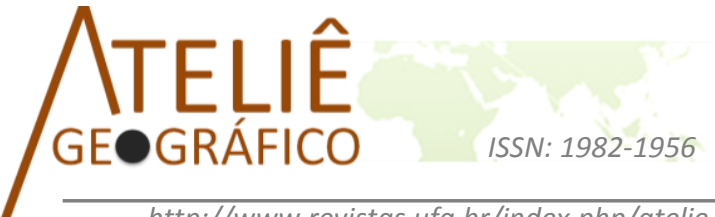 \\ http://www.revistas.ufg.br/index.php/atelie
}

\section{A Geografia e o Sagrado: Festa de Nossa Senhora do Rosário em Goiás}

\author{
Geography and the sacred: Our Lady of the Rosary feast in \\ Goiás

\section{La Geographie et le sacré: Fête de Notre Dame du Rosaire dans Goiás}

Mary Anne Vieira Silva

Universidade Estadual de Goiás

Maryme12006@hotmail.com

Maria Idelma Vieira D'Abadia

Universidade Estadual de Goiás

midabadia@bol.com.br

\begin{abstract}
Resumo
As festas religiosas na contemporaneidade tornam-se dinamizadoras de articulações das ordens social, simbólica e cultural e são capazes de promover profícuas relações sociais que se materializam no plano espacial. $\mathrm{O}$ catolicismo popular garante a constituição de uma teia de significados vivida e vivenciada nos e pelos diversos ritos e ritualísticas essenciais do espaço das festas religiosas, aqui em especial, as de padroeiros(as). No estado de Goiás, essas celebrações, sobretudo, as pertencentes a vertente do catolicismo popular, apresentam-se como ligas identitárias. Elas perpassam as práticas eminentemente religiosas traduzindo-se como vínculos territoriais estabelecidos entre o habitante/devoto, o não-habitante/devoto com o lugar da festa. Para o presente texto ocorrerá uma análise sobre a festa de Nossa Senhora do Rosário em Goiás, santa padroeira de três municípios e comemorada em outros quinze municípios por meio de congadas, folias e reinados. Metodologicamente, o recorte espacial para a análise é delimitado às cidades de Pirenópolis e Monte Alegre. Objetiva-se apresentar a referida festa por meio da teia simbólica traduzida nas imagens, bem como pela valorização dos roteiros de observações construídos durante as visitas in loco.
\end{abstract}

Palavras-chave: Reinado do Rosário, festa religiosa, Pirenópolis, Monte Alegre de Goiás. 


\begin{abstract}
The religious feasts nowadays have become driving forces of articulations of symbolical, cultural and social orders and are able to promote positive social relations which materialize on the spatial plan. Popular Catholicism ensures the constitution of a web of meanings lived and experienced in and by several rites and ritualistic practices which are essential for religious feasts. Particularly here, the patron saints ones. In the state of Goiás, these celebrations, especially those belonging to the popular Catholicism are presented as identity binds. They surpass practices which are eminently religious by translating into territorial links established between resident/devotee and non-resident/devotee to the place of the feast. The present text will present an analysis of the feast of Our Lady of the Rosary, the patron saint of three municipalities in Goias, also celebrated in fifteen other municipalities in the form of regional feasts (congadas, follies and reigns). Methodologically, the spatial cutting for the analysis is delimited to the cities of Pirenópolis and Monte Alegre. The goal is to present the referred feast through a symbolic web translated into the images, as well as by an appreciation of the observation criteria built during on-site visits.
\end{abstract}

Key words: Rosary reign, religious feast, Pirenópolis, Monte Alegre de Goiás

\begin{abstract}
Resumé
Les fêtes religieuses dans la contemporanéité sont devenu facilitateurs des articulations des ordre social, symbolique et culturel et sont capables de promouvoir relations sociaux frutueux que se matérialisent dans le plan spatial. Le catholicisme populaire assure la constitution d'une toile de significations vecú et experimenté dans et pour les divers rites et ritualistes essenciaux de l'espace des fêtes religieuses, en special ici, les une de saintes patrons. Dans l'état de Goiás, cettes célébrations, surtout lequelles qui appartient au catholicisme populaire, elles se present comme alliages d'identité. Elles imprègnent les pratiques plutot religieuses, en se traduisant comme des liens territoriaux établis entre l'habitant/devote, le non habitant/devote avec le lieu de la fête. Pour ce present texte se produira une analyse sur la fête de Nossa Senhora do Rosário dans Goiás, la sainte patron de trois municipalités et celebré dans autres quinze municipalités par des célébrations religieuse regionaux. Comme méthodologie le coupe spatial pour l'analyse est delimite à deux villes, Pirenópolis et Monte Alegre. L'objectif est de presenter cette fête par une toile symbolique traduit dans les images, aussi bien que par l'appréciation des scénarios d'obervation construit durant les visites in loco.
\end{abstract}

Mots Clés: Royaume de Rosário, fête religieuse, Pirenópolis, Monte Alegre de Goiás.

\title{
Introdução
}

A geografia cultural, em um marco temporal que envolve as duas décadas finais do século XX e a primeira do século XXI, notadamente se apresenta com profundas reflexões conceituais e epistemológicas, a partir de diversas concepções, que englobam vários substratos teóricos, sentidos políticos que, embora foquem a dimensão espacial da cultura, podem conflitar. No que concerne ao tratamento dos campos simbólicos produzidos pelas representações espaciais e pelas subjetividades, as festas assumiram na agenda da geografia cultural espaços investigativos que promovem enriquecedoras 
análises. Perceptivelmente, elas provocam debates no seio das ciências humanas gerando interpretações para o entendimento do ser humano e da produção do mundo simbólico por ele produzido.

Essas festas se fazem em contextos espaciais múltiplos, sobretudo, produzindo o espaço simbólico da fé, da devoção, enfim, o próprio espaço religioso. Aponta-se para corroborar tal afirmativa, os estudos de Claval (2002; 1999), Almeida (2011; 2009), Rosendahl (2002; 1997) e Gil Filho (2008). Tais estudos, respeitando as vias teórico-conceituais desses autores, hoje, garantem uma configuração interpretativa múltipla das relações entre o ser humano, o espaço e o sagrado. Nesses estudos são recorrentes reflexões que se descortinam por várias abordagens metodológicas, a saber: fenomenologia, hermenêutica, existencialismo, idealismo e outras. Campos de investigação e reflexão que possibilitam adentrar nas concepções de fenômenos, aqui culturais, permitindo interpretações plurais sobre as relações subjetivas produzidas e os significados das ações do ser humano no tempo e no espaço.

\section{A geografia cultural e as festas religiosas}

As festas religiosas são relevantes aos estudos da geografia cultural, por serem produzidas e produtoras de uma teia de significados que exprime os sentidos da própria cultura, pois conforme afirma Almeida (2009, p.259), "desde o início da década de 1990, os estudos com abordagem na geografia cultural têm sido fecundos com as representações de "outros" lugares e paisagens. Sem dúvida, são ricos e desafiadores os cenários futuros para aqueles que estão investigando os mundos culturais".

Esses mundos culturais são produções simbólicas. E quem atribui diretamente os sentidos e os significados são aqueles que deles participam como devoto, visitante, organizador e outros. Na perspectiva da geografia cultural a festa promove a reconstrução de 'outros' espaços e tempos, os festivos. Esses são carregados de sentidos e de significados contrários aos tempos do cotidiano.

Para Almeida (2008, p.44), o entendimento na contemporaneidade desse campo interpretativo da geografia cultural permite "discutir de forma mais ampla as maneiras como os artefatos materiais são apropriados e como os seus significados transformados". Essa concepção passa a empreender uma importância para a análise da ordem simbólica das manifestações, uma vez que essas dão sentidos ao lugar por meio de um sistema de linguagem estabelecido pelos signos produzidos. Os signos se traduzem em símbolos territoriais de pertencimentos. A dimensão estabelecida pelo sentimento de pertença constrói uma liga que se dá territorialmente. Para Di Meó (2001), essa dimensão gerada 
pela festa cria uma identidade territorial e para a geografia se desdobra como um campo específico de análise, o qual é produzido pela festa, o habitante e o lugar por meio de símbolos territoriais.

As festas religiosas como produtoras de símbolos territoriais se constituem na prática por vários fatores. Elas se apresentam com uma ordenação rígida controlada pelo grupo religioso que a propõe e marca, simbolicamente, a presença muito viva de uma hierarquia em nome do sagrado. Outro fator gerador desses símbolos remete-se ao fato da festa permitir a orientação de sinais espacializados produzidos pelos grupos que dela participam historicamente. Seria na interpretação de Di Méo (2001), a produção de marcos territoriais identificada pelos grupos em contextos geográficos específicos. São os marcos que garantem uma singularidade a cada festa.

Em determinados contextos históricos, para o caso brasileiro, as festas ligadas a vertente cristã católica possibilitaram marcas identitárias que se institucionalizaram a partir do governo português e da Igreja no período Colonial. Ressaltamos o culto aos santos ${ }^{1}$ como uma das principais marcas de vínculos territoriais. Para a geógrafa D’Abadia (2010) as festas religiosas de padroeiros em suas estrutura e diretriz conseguiram garantir um calendário anual de festividades de santos interligando práticas auríferas, pastoris e agrárias.

A autora demonstra que essa condição foi expressa na fundação dos arraiais e vilas, que nasceram protegidos pelos inúmeros santos do culto católico. Recebendo nome de um santo, ou sendo influenciadas pela religião, muitas cidades tiveram suas denominações ligadas ao padroeiro; algumas modificando de nome, outras perpetuadas até hoje com essas designações.

Pela singularidade e certo distanciamento de outras influências, as festas religiosas católicas em Goiás demonstram o quanto a formação cultural do povo goiano foi relevante para seu surgimento e para a manutenção desses eventos que hoje estão presentes no calendário turístico do estado.

\footnotetext{
${ }^{1}$ A definição comumente aceita de santos, entre os católicos, é que são aqueles indivíduos que viveram uma vida exemplar na terra e a quem a Igreja Católica determinou que estivessem com Deus. Os santos são mais comumente conhecidos pelo martírio, virtude heroica e milagres. Como resultado desses dons, católicos em todo o mundo rezam aos santos e os honram celebrando seus dias festivos, mencionando-os de tempos em tempos na celebração da Missa, colocando estátuas e pinturas deles, entesourando seus pertences mundanos, bem como seus restos físicos, e dando os nomes deles aos seus filhos e a suas igrejas. O processo pelo qual a Igreja Católica determina quem é santo é chamado de canonização (D’ABADIA, 2010).
} 


\section{O sagrado simbólico: um campo investigativo em discussão}

$\mathrm{Na}$ contemporaneidade o mundo representado pelas subjetividades ganhou corpo teórico na geografia a partir de abordagens que tratam dos espaços de vivência, de experiência e de representação, sobretudo, as simbólicas. O sagrado em termos de concepção teórica é interpretado na história por alguns aspectos sui generis. Para Gil Filho (2008, p.28), "o resgate do sagrado é a tentativa de encontrar o âmago da experiência religiosa", o que ocasiona uma ligação direta entre o ser religioso e sua prática. Assim, a dimensão religiosa situa-se em um contexto cultural em que a manifestação do sagrado se impõe e se revela a partir de dinâmicas espaços-temporais.

Isto posto, infere-se que essa concepção de sagrado é dada enquanto forma de conhecimento sobre o mundo e que se posiciona como expressão alternativa à razão. Coloca-se, portanto, como via interpretativa da significação de dada realidade. Nesse sentido, o sagrado situa-se entre a racionalidade dos ditos materiais simbólicos e a irracionalidade do sentimento religioso.

O sagrado, segundo essa perspectiva apresentada, é entendido como forma e conteúdo de dada cosmovisão e de suas ocorrências nos diversos planos subjetivos e objetivos. Para melhor compreender essa concepção, afirmamos que o rito garante essa ambivalência presente na prática do sagrado. O rito é posto no centro da concepção do sagrado e torna-se a própria ocorrência do princípio hierofânico.

As contribuições que advêm dos centros difusores da geografia cultural brasileira, que hoje produzem estudos significativos para o desvendamento e o entendimento do sagrado, apontam que "o ser humano, ao aceitar a hierofania, experimenta um sentimento religioso em relação ao objeto sagrado [...] uma disponibilidade ao divino" (ROSENDHAL, 2002, p.27).

Desta feita, o sagrado só se realiza na sua condição de fenômeno religioso quando relacionado a um momento religioso, e isso só é possível quando ocorre a inserção do indivíduo nessa realidade. Daí pensar que o sagrado existe para quem dele participa e dele experiencia.

A partir dessa compreensão é possível propor uma abordagem em que se observe a emergência de uma dualidade na constituição do espaço em seu sentido hierofânico. De um lado, constrói-se, a partir da vivência dos entes religiosos, um espaço sagrado, dotado de hierofanias e sentimentos religiosos. Em oposição, opera-se um entorno que, direta ou indiretamente, vincula-se a essa posição e que a ela se opõe. Conforme Rosendahl (1997, p.122), "é possível distinguir dois elementos fundamentais no espaço sagrado: o "ponto fixo' e o seu entorno". A partir dessa contribuição temos a ocorrência do 
sagrado em uma dada espacialidade - o ponto fixo e o entorno formando o que se considera como profano.

As festas religiosas ligadas ao credo católico promovem a ocorrência dessa dupla espacialidade que se amalgama em determinados contextos espaciais e temporais. As festas de padroeiros(as) são uma complexa representação simbólica de tempos e espaços sagrados e profanos. Ao retomarmos o estudo clássico de Eliade (1998), o espaço sagrado se estabelece na repetição da hierofania primordial que o sacraliza. Essa ocorrência dá-se nos objetos ou nas pessoas, e de certa forma, a hierofania é vivenciada por meio de uma separação entre o espaço sagrado e aquele designado por profano - o entorno. A ocorrência de uma festa religiosa já revela essa dupla concepção do espaço e do tempo das práticas sagradas e das profanas. $\mathrm{O}$ espaço da festa se traduz na convergência e na coexistência de múltiplos significados produzidos pelo ser religioso.

Para Eliade (1999), toda festa religiosa, todo tempo litúrgico, representa a reatualização de um evento sagrado que teve lugar em um passado mítico. A vivência da festa religiosa oportuniza ao ser a saída momentânea do tempo e do espaço profano e sua inserção nas dimensões que designam os sentidos míticos sagrados. O sagrado se faz por um rígido ordenamento do tempo e do espaço sacros. Mas esse ordenamento permite as continuidades dos espaços profanos, devido o principal intermédio garantido pela função social de uma festa, a de espaço organizativo de coletividades.

\section{A festa de padroeiro como sentido-símbolo da organização da vida}

A festa de padroeiro no Brasil, e mais tarde em Goiás, ganha relevo no sentido de estabelecer uma relação de proximidade e vínculo territorial dos santos aos territórios ocupados e organizados sob a perspectiva do reino de Portugal. Ela se constituiu por meio das práticas auríferas e agropastoris na ocupação do território e na organização de uma cultura religiosa de comemorações aos santos e padroeiros. E esses, por meio de um calendário especial, estabelecido pela Igreja Católica, como já dito, levaram e ainda levam, nas cidades e municípios goianos, inúmeras pessoas a se envolverem de forma direta e indireta com as festas comemorativas que homenageiam os santos de maneira geral e os padroeiros.

Embora para alguns autores a festa se apresente ressignificada, ou seja, com nova importância e valor, por exemplo, Santos (2008) ao estudar as festas do Cerrado mineiro enfatiza as transformações ocorridas nessas festas tradicionais e o novo sentido de espetáculo que elas ganham num universo coletivo diversificado e não mais comunitário. 
A festa, na sua característica quase que totalmente religiosa, transfere, para a comunidade e para o sobrenatural, a possibilidade de reprodução dos homens. Mas, com as imposições do mercado sobre as festas antigas, a festa tende para o espetáculo [...] porque "os participantes", em geral, são conclamados a assistir, a ver! No entanto, enquanto existirem aqueles que lembram, que praticam a festa e a oferecem à coletividade (conjunto de pessoas, não se trataria mais de comunidade), ela sobreviverá, determinando-se positivamente (SANTOS, 2008, p. 200-201).

O autor expõe a festa como possibilidade de reprodução dos homens. Uma festa que se organiza na construção de uma memória ressignificada na atualidade, mas ainda preservada no sentido simbólico, que aproxima os participantes da comunidade local e também os elementos externos pertinentes aos frequentadores de festas.

Para Lobo (2006), embora ocorram transformações ao longo do tempo, as singularidades dos lugares festivos possibilitam a interpretação dos significados simbólicos das festas e a manifestação dos valores identitários. As festas de padroeiros constituem espaços de socialização e pertença dos envolvidos, dos devotos, dos moradores, dos participantes. A festa religiosa envolve os grupos humanos sejam religiosos ou não. É um elemento agregador de pessoas.

D'Abadia (2010, p. 23), explora o sentido das romarias como um exemplo de práticas religiosas que persistem e "ajustam-se pela vontade e fé dos indivíduos leigos" levando a uma organização comunitária para a devoção e prática do rito festivo, ou seja, "os devotos se fortalecem pela prática religiosa, pela devoção e pela divulgação do milagre dos santos". As romarias e outras festas religiosas são espaços de múltiplas vivências e experiências do humano.

Nesse sentido, apresenta-se como espaços de múltiplas vivências e experiências humanas os casos de duas festas religiosas atribuídas a Nossa Senhora do Rosário em Goiás e que agregam valores, tradições e elementos contemporâneos em cidades do ciclo de mineração goiano: Pirenópolis e Monte Alegre de Goiás.

\section{A festa do Rosário em Pirenópolis: duas igrejas e uma mesma devoção}

A homenagem aos santos católicos era comum na descoberta das minas, fruto de uma relação intensa em o Estado Português e a Igreja Católica nas suas possessões ultramarinas em outros continentes fora da Europa. A tradição católica foi difundida no Brasil por meio da denominação dos lugares 
das novas posses portuguesas e também como uma forma de espalhar a fé católica, além da busca de riquezas materiais, a qual era um dos objetivos da conquista de novas terras ao Reino.

Nesse contexto surgiu proximamente a outubro de 1727 o arraial de mineração denominado Minas de Nossa Senhora do Rosário de Meia Ponte. No período em questão a mão de obra para o trabalho de exploração do ouro era a africana escravizada. Essas relações desiguais também geravam no meio social separação na forma de praticar os rituais católicos, pois não havia proximidade dos entre senhores donos de escravos e estes no meio público. No entanto, a crença do senhor de escravo era imposta a essas pessoas. A forma comum de organização das igrejas era a criação de irmandades em que congregavam tanto livres, quanto escravos. Essas provocavam na sociedade uma fé religiosa dicotômica em relação aos seus praticantes.

No caso analisado foram erguidas no arraial duas igrejas em homenagem a Nossa Senhora do Rosário. A matriz do Rosário foi construída na praça central do arraial e era frequentada pelo grupo dominante de predomínio branco. Nessa igreja ainda acontece, regularmente todos os anos, em outubro, a festa em homenagem a Nossa Senhora do Rosário, padroeira da cidade atualmente denominada Pirenópolis. Nessa festa alguns elementos são pertinentes. Desses destacamos a imagem de Nossa Senhora do Rosário, ícone da devoção mariana, a imagem torna-se o centro da veneração no rito da procissão. Outro elemento que ressaltamos são as mulheres da irmandade que levam o andor ornamentado, essas geralmente, representam o ideário de mãe, sobretudo pela devoção à Senhora do Rosário. Nesse contexto do culto aparece a bandeira do mastro com a estampa de N. S. do Rosário; o mastro é a marca no território responsável por reforçar simbolicamente a territorialidade mariana no local. A devoção é simbolicamente demarcada pelas ofertas, e se traduzem por atos de gratidão, e em formas de pagamento de promessas. Os devotos, em sua maioria, realizam novenas, procissões, leilões e festas.

Num sentido litúrgico a festa é organizada a partir da novena, na qual são celebradas missas, quermesses, shows musicais, levantamento do mastro e procissão de encerramento. Nessa festa há uma forte relação da igreja com a comunidade. Essa relação é fruto das mudanças ocorridas, de certa forma, recentes na organização da Igreja Católica na contemporaneidade, visando uma atitude positiva para com os fieis a igreja incentiva as quermesses e festas dentro dos rituais católicos com a participação de todas as pastorais, promovendo assim um movimento mais assíduo e continuo de seus membros em atividades cotidianas festivas.

Já a segunda igreja em homenagem a Nossa Senhora do Rosário ficou conhecida como Igreja de Nossa Senhora do Rosário dos Pretos. Ela foi 
edificada pelos escravos e negros forros entre os anos de 1743 e 1757 (CURADO, 2012) e demolida em 1944 (BRANDÃO, 1978). No entanto, os rituais de homenagem ao Rosário ainda permanecem relacionados aos antepassados. Mesmo não existindo a Igreja de Nossa Senhora do Rosário dos Pretos e a Irmandade de Nossa Senhora do Rosário dos Pretos, formada em 1758, os festejos, na atualidade, continuam ligados à tradição local, contando em sua maioria, com a presença de pirenopolinos que têm identificação individual e coletiva com o momento.

De acordo com Lobo (2006), ao longo do tempo, o Reinado sofreu constantes redefinições e reelaborações: festas de negros dos séculos 18 e 19, transformaram-se em festas de brancos pobres, até chegar hoje à manifestação cultural da qual participam pirenopolinos pertencentes às mais diversas classes sociais. Os partícipes são diversificados e, mesmo não tomando parte como atores centrais, rei, rainha, juiz ou juíza, contribuem para a realização e a ampliação dos festejos.

Essa festa do Rosário dos Pretos foi incorporada aos festejos do Divino há mais de um século e é realizada na segunda-feira após o domingo do Divino. A sua prática consiste da nomeação do rei e da rainha do Rosário pelo "andador" do Reinado, Geraldo Herculano de Oliveira, de acordo com o relatório do IPHAN (2008). O ritual do Reinado inicia-se com o cortejo de busca, em suas casas, do rei e da rainha do Rosário. Esse cortejo era feito, no passado, pelos negros acompanhados pela Banda de Couro $^{2}$ e Congado. Esses eram levados até a Igreja do Bonfim, onde seria celebrada a missa em homenagem a Nossa Senhora do Rosário dos Pretos. Após a missa o cortejo seguia para a casa da rainha para a distribuição dos alimentos e licores aos participantes, a distribuição da bebida, dos doces e dos salgados é relacionada à mesa farta presente nas festas goianas. Essa dinâmica ritual era praticada no passado e ainda segue no presente.

A presença da comida na festa do Rosário ganha um valor simbólico adicional, não apenas o processo da alimentação em si. Ela reflete a tradição gastronômica das festividades locais. Tradição essa em que, receitas, modos de fazer, ingredientes, saberes e trocas são preservados. A comida da festa é o resultado da produção de famílias que seguem uma representação das tradições alimentares locais. E vale apontar, nesta perspectiva, que para a maioria das pessoas envolvidas, os alimentos não constituem apenas um item de consumo, eles refletem escolhas gastronômicas relacionadas ao estilo de vida, aos aspectos simbólicos e imateriais dos devotos e simpatizantes do Reinado de Nossa Senhora do Rosário. Da Mata (1998) ressalta que, as tradições

\footnotetext{
${ }^{2}$ Banda com instrumentos feitos a base de couro bovino. Produz sons de tambor e percussão.
} 
alimentares, a questão do espaço e das relações sociais envolvem a comida como elemento de identidade,

\begin{abstract}
Mas a comida é algo que define um domínio e põe as coisas em foco. Assim, a comida é correspondente ao famoso e antigo "decomer", expressão equivalente a refeição, como de resto é a palavra comida. Por outro lado, comida se refere a algo costumeiro e sadio, alguma coisa que ajuda a estabelecer uma identidade, definindo, por isso mesmo, um grupo, classe ou pessoa (DAMATTA, 1986, p. 45).
\end{abstract}

Nesse sentido a comida das festas representa as relações de produção material e simbólica, traduzindo a cultura daquela região e daquele povo. Atualmente essa festa conta com a participação intensa da comunidade católica local de Pirenópolis e visitantes promovendo um entrelaçamento identitário na população pirenopolina. A festa do Reinado representa o sentido de pertencer ao lugar, promove uma peculiaridade expressa em suas tradições.

\title{
Monte Alegre de Goiás: O Reinado da rainha do Rosário e o Reinado da Cachaça
}

Monte Alegre é um município do Nordeste Goiano que surgiu em meados do século XVIII como arraial de mineração, denominava-se Santo Antônio do Morro do Chapéu. Em 1953 recebeu a denominação atual de Monte Alegre de Goiás. Atualmente a população dedica-se principalmente as atividades agropastoris, e de acordo com o IBGE (2010), têm um alto índice de pobreza e baixo desenvolvimento, fato constatado nas entrevistas feitas com participantes da festa ${ }^{3}$. Dadas as condições materiais do local a festa também proporciona aos moradores certo dimensionamento econômico com o movimento de pessoas gerando renda extra e um pequeno comércio informal aos moradores.

O santo padroeiro da paróquia e da cidade de Monte Alegre é Santo Antônio que é homenageado em sua data comemorativa. No entanto, é na festa do Rosário que as relações sociais se estreitam e ganham corpo de ajuntamento e rememoração juntando passado e presente nesses dias festivos.

Associadas ao ciclo do ouro, as festas do Rosário estão relacionadas ao culto católico dos negros escravizados no Brasil. As regiões remanescentes de áreas de mineração, em Goiás, têm preservado ainda nos tempos atuais os festejos do Rosário, sejam em folias, congados, reinados ou novenas.

\footnotetext{
${ }^{3}$ Trabalho de campo Pró-Cultura - julho de 2012.
} 
As comemorações do Rosário em Monte Alegre de Goiás, de acordo com o programa da festa em 2012, são realizadas há 274 anos. Atualmente, nessas comemorações, apresenta-se a formação da corte real pelo Congado, a Sussa, a Cavalaria, o Rei e a Rainha do Rosário. Tradição religiosa de longa data na cidade, a festa do Rosário consiste em uma novena realizada em homenagem à Maria e a prática de rituais agregados a essa festa. Esses rituais estão ligados à dança de congado formado por integrantes da população local, bem como à sussa, dança de origem africana pesquisada por Siqueira (2006) na comunidade Kalunga de Santa Terezinha de Goiás, município vizinho de Monte Alegre.

Tanto os homens como as mulheres cantam a sussa, mas há um repertório mais masculino e outro mais feminino. Algumas músicas são mais cantadas por mulheres e outras mais cantadas por homens, embora não creio que existam sussas excludentes, o que se vê é que algumas são preferidas por um sexo e preteridas por outro. A dança da sussa feita pelo homem e a mulher (que presenciei apenas rapidamente) é uma espécie de desafio. A mulher avança em direção ao homem e vice -versa, de forma que as 'forças' se equilibrem na dança, há o avanço e o recuo, o avanço e o recuo e assim sucessivamente.[...]A sussa é uma dança que pode ser feita em qualquer ocasião, geralmente acompanha a folia, depois de cantados os cantos 'sagrados' e pode compor a parte 'profana', assim como a curraleira, a valsa (não mais praticada por eles) e o forró. Mas pode acontecer em outras ocasiões, como as meras brincadeiras dos jovens ("moçadinha") na beira do rio ou nos campos: a sussa acima de tudo é uma brincadeira, uma diversão. Na vida rural dos kalunga de certo tempo atrás em que não tinha energia elétrica e em que o maior passatempo era o trabalho, a sussa era a grande diversão, reunia crianças, jovens e adultos dentro do universo lúdico e musical. $\mathrm{Na}$ época da seca, em que contava-se com a chuva para que a próxima colheita viesse com fartura, podia-se dançar a sussa para que 'Deus' trouxesse a chuva para eles.( SIQUEIRA, 2006, p. 93)

Dança típica das comunidades Kalunga, a sussa foi incorporada pelas populações locais do Nordeste Goiano e hoje é dançada também como espetáculo em apresentações culturais de grupos provenientes dessas localidades. A seguir apresenta-se uma descrição de momentos de formação do Reinado na festa de 2012. A representação aqui envolve aspectos diferentes em relação ao Reinado do Rosário na cidade de Pirenópolis. O envolvimento dos organizadores da festa se impõe como condição de visibilidade social e política na cidade. Essa condição se apresenta nos aparatos dos desfiles, na ornamentação do local e nas vestimentas do rei e da rainha.

Nessa festa a forma de organizar a escolha da rainha é por sorteio, ou promessas. A dita-cuja escolhida geralmente é uma pessoa de condições 
econômicas bastante elevadas na cidade, visto ao montante de recursos que irá gastar com a festa. Embora recebam patrocino do comércio local, a maior fonte de recursos provem dos laços de amizades, familiares e amigos que investem no evento e o tornam bem requintado para as condições socioeconômicas presente na cidade. Daí a festa, em Monte Alegre, ser uma reunião de pessoas com diversos interesses, mas unidos por uma identidade de pertencimento para com o lugar e para com a festa.

Concomitante ao Reinado do Rosário aconteça, no mesmo período, o chamado "Reinado da Cachaça". Proposto por jovens, no mesmo formato do reinado religioso, o evento é uma sátira a festa religiosa; nele são coroados os reis e as rainhas de todos os anos, eles são os responsáveis diretos pela organização da festa que inclui: contratação de bandas, organização do local, busca de patrocinadores e confecção dos abadás. o que, de certa forma, ressalta os interesses econômicos dos organizadores, levando a disputas pelas funções na festa.

Atualmente o Reinado da Cachaça consiste de um carnaval fora de época que congrega bastante jovens, principalmente brasilienses, e que se realiza no município há mais de vinte anos. O carnaval fora de época foi uma invenção do final dos anos 80 e inicio dos anos 90, corresponde a um produto criado a partir de um elemento da indústria cultural, a música. Nesse contexto ocorreu uma explosão da axé music ou música baiana em todo o Brasil, que levou ao sucesso do carnaval baiano e, consequentemente, em se pensar em vários carnavais fora de época ou micaretas, como ficaram conhecidas (MENEZES, 2004).

Nessa festividade ocorre a comercialização dos abadás e outras práticas referentes à organização especifica para uma carnaval fora de época. Xavier e Maia $(2009$, p. 224) ressaltam que apesar das críticas, "a adesão dos foliões ao abadá cresce cada vez mais, sendo manifestada também em micaretas fora de época, ou festas fechadas que utilizam como parte do ingresso o abadá". Ademais, em Monte Alegre ocorre uma dinâmica expressiva da participação dos grupos locais no contexto das duas festas, proporcionando relações ora de proximidade, ora de conflitos na localidade.

Essa festa aparece no contexto local como uma contraposição da festa religiosa do Reinado do Rosário, centenária no município. Esse "reinado" leva uma grande quantidade de pessoas à cidade e inúmeras desconhecem a tradicional festa do Rosário. Em depoimentos colhidos junto a jovens que estavam de passagem na praça central da cidade, onde eram celebradas as festividades da rainha do Rosário, eles afirmam que nunca tinham participado da festa religiosa e estavam na cidade para o Reinado da Cachaça. 


\section{Considerações finais}

As festas religiosas em Goiás demarcam os locis de contextos espaciais múltiplos, sobretudo, produzindo o espaço simbólico da fé e da devoção. O espaço religioso promove a permanência dessas práticas que com sua continuidade causam a liga do território capaz de reforçar os laços indenitários em diferentes locais. As territorialidades produzidas pelas festas de Nossa Senhora do Rosário nas cidades Monte Alegre e Pirenópolis são representações das invocações marianas que formam um conjunto diverso de denominações de Maria, cultuadas como santas em espaços específicos consagrados.

A festa de Nossa Senhora do Rosário é vivenciada por meio de experiências que se exprimem com a ocorrência do sagrado. Perceptivelmente, o ser humano se permite em seu ato de devoção e fé partilhar de inúmeras manifestações hierofânicas durante as cerimônias. São diversas as ocorrências em que o sagrado se revela durante uma festa religiosa, no nosso caso, a santa mencionada.

A ritualística já garante a imbricada relação do ser religioso com o sagrado pertencente. Há uma ordem de reconhecimento do sagrado durante a manifestação, seja na adoração à imagem, que sempre é carregada pelo simbolismo de buscar o poder do divino representado, seja por participar do conjunto de atos devocionais Enfim, são os sentimentos, as ações, os símbolos pensados e construídos que constituem os espaços em uma dimensionalidade sagrada, sobretudo, nos lugares, onde se praticam a devoção. A partir dessa concepção é que se aponta a festa como ligação espacial e territorial da identidade religiosa.

As observações obtidas durante a festa estudada apontam para a reflexão de que o sagrado designa a ocorrência do próprio espaço sagrado. Assim, os símbolos, os mitos, os ritos, as festas se configuram como reforçadores de uma identidade territorial, assim como expõe o geógrafo Di Méo (2001) e D'Abadia (2010). Para o Di Méo, “o espaço territorializado pela festa entra em uma configuração simbólica, ao mesmo tempo efêmera (temporária então) e reproduzível (ritmo cíclico das festas)".

$\mathrm{Na}$ festa, a intensidade da vivência religiosa relaciona-se aos dias de maior calor espiritual, emocional e religioso. Nela há outro significado além do visível, pois ocorre uma complementação da materialidade e da espiritualidade humana. A identidade é criada nesses laços invisíveis e visíveis que promovem um entrelaçamento de experiências e emoções que transcende $o$ cotidiano, o ordinário. A festa tem um sentido próprio dado pela natureza humana. 
Nas festas de santos católicos, a materialidade e a espiritualidade estão presentes tanto no espaço sagrado quanto no profano. O que acarreta um estágio de profunda imbricação entre ambos. Quando uma festa tem a tendência de evidenciar apenas um dos lados, ela começa a passar por mudanças muito significativas que podem levar ao seu desaparecimento ou estabelecimento de outros sentidos para os locais de festividades. Ou seja, as festas podem tornar-se espetáculos para os visitantes. Para Di Méo (2001, p.58):

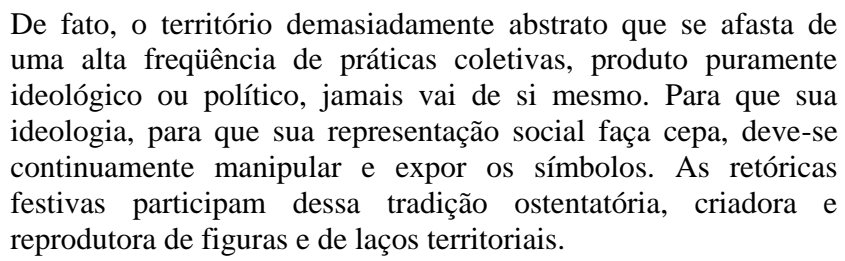

A identidade territorial garantida pela festa de Nossa Senhora do Rosário está representada na religiosidade dos devotos e na apropriação simbólica expressiva dada para aqueles espaços.

\section{Referências}

ALMEIDA, M. G. Geografia Cultural: contemporaneidade e um flashback na sua ascensão no Brasil. In: MENDONÇA, F; LOWEN-SAHR,C.L;SILVA, M (orgs.) Espaço e tempo. Complexidade e desafios do pensar e do fazer geográfico. Curitiba. ADEMADAN, 2009.

ALMEIDA, M. G. Aportes teóricos e os percursos epistemológicos da geografia cultural. In: Geonordeste. Núcleo de Pós-graduação em Geografia. Universidade Federal de Sergipe. São Cristovão-SE. Ano XIX, n.1. jul/2008.

ALMEIDA, Maria Geralda de. Festas Rurais e Turismo em Territórios Emergentes. 2011. http://www.ub.edu/geocrit/b3w-919.htm

ALMEIDA, Maria Geralda de; MUNDIM, Maria Augusta; MENDES, Geisa Flores. Territórios, Paisagens e Representações: um diálogo em construção (territories, landscapes and representations). Revista Mercator, Fortaleza; v. 10, n. 22, p.23-35, mai./ago, 2011.

BRANDÃO, Carlos Rodrigues. O Divino, o Santo e a Senhora. Rio de Janeiro, FUNARTE, 1978, 163p. 
CURADO, João Guilherme da Trindade, LÔBO, Tereza Caroline. A híbrida religiosidade negra nos festejos do Reinado e Juizado em Pirenópolis-GO. Texto apresentado no V Simpósio Internacional do Centro de Estudos do Caribe no Brasil: Fronteiras em Movimento: África - Brasil - Caribe. Salvador, Bahia. Set/Out - 2008.

CURADO, J. G. Apontamentos sobre os negros em Meia Ponte nos séculos XVIII e XIX. VI Simpósio Nacional de História Cultural Escritas da História: Ver - Sentir - Narrar. Universidade Federal do Piauí - UFPI Teresina - PI, 2012. Disponível em

http://gthistoriacultural.com.br/VIsimposio/anais/Joao\%20Guilherme\%20da\%2 0Trindade\%20Curado.pdf Acesso em 31/07/2013.

CLAVAL, P. Campo e perspectiva da geografia cultural. Trad. Márcia Trigueiro. In. CORRÊA, R.L; ROSENDAHL, Z.(orgs). Geografia Cultural: um século (3). Rio de Janeiro, Eduerj, 2002.

CLAVAL, P. A Geografia Cultural. Florianópolis, Editora da UFSC, 1999. D'ABADIA, M. I. V. Diversidade e Identidade Religiosa: uma leitura espacial dos padroeiros e seus festejos em Muquém, Abadiânia e Trindade-GO. 260 f. Tese (Doutorado em Geografia). Instituto de Estudos Socioambientais, UFG, Goiânia, 2010.

DA MATTA, Roberto. O que faz o brasil, Brasil?. 2 ed. Rio de Janeiro, RJ: Editora Rocco Ltda., 1986.

DI MÉO, G. La Géographie em Fêtes. Paris,Ophrys, 2001.

ELIADE, M. Tratado de História das Religiões. São Paulo, Martins Fontes, 1998.

Martins Fontes, 1999.

O sagrado e o profano. Trad. Rogério Fernandes. São Paulo.

GIL FILHO, S. F. Espaço Sagrado; estudos em geografia da religião. Curitiba, IBPEX, 2008.

GIL FILHO, S.F. et all. Identidade religiosa e Territorialidade do Sagrado: notas para uma teoria do fato religioso. In: Corrêa, R.L. ROSENDAHL, Z (Orgs) Religião, Identidade e Território. Rio de Janeiro. EDUERJ, 2001. 
LÔBO, Tereza Caroline. A Singularidade de um Lugar Festivo: O Reinado de Nossa Senhora do Rosário dos Pretos e o Juizado de São Benedito em Pirenópolis. 152 f. Dissertação (Mestrado em Geografia) Instituto de Estudos SocioAmbientais, UFG, Goiânia, 2006.

MENEZES, Paula Dutra Leão de. Gestão Turística e Questões Culturais. In: Turismo - Visão e Ação. Itajaí, vol. 6, n.1 p.115-124, jan/abril 2004, Disponível em http://www6.univali.br/seer/index.php/rtva/article/viewFile/1057/866 Acesso em 10/04/2014.

ROSENDAHL, Z. Território e Territorialidades: uma perspectiva geográfica para o estudo da religião. In: CORRÊA, R.L; ROSENDAHL, Z (orgs). Geografia: temas sobre cultura e espaço. Rio de Janeiro.EdUERJ ,2005,pp191226.

ROSENDAHL, Z. Espaço, Política e Religião. In: CORRÊA, R.L; ROSENDAHL, Z (orgs). Religião, Identidade e Território. Rio de Janeiro.EdUERJ ,2001,pp200.

ROSENDAHL, Z. O sagrado e o espaço. In: CASTRO, I. E; CORREAA, R.L; ROSENDAHL, Z (orgs). Explorações geográficas. Rio de Janeiro. Bertrand Brasil, 1997,pp 119-154.

SANTOS, R. J. Gaúchos e Mineiros do Cerrado: metamorfoses das diferentes temporalidades e lógicas sociais. Uberlândia: EDUFU, 2008, 249p.

SIQUEIRA, T. T. Do tempo da sussa ao tempo do forró: Música, festa e memória entre os Kalunga de Teresina de Goiás. 135 f. Dissertação (Mestrado em Antropologia Social). Instituto de Ciências Sociais, Departamento de Antropologia, UNB, Brasília, 2006. Disponível em http://repositorio.unb.br/bitstream/10482/3496/1/Disserta\%C3\%A7\%C3\%A3o $\% 20 \mathrm{de} \% 20 \mathrm{Mestrado} \% 20 \mathrm{de} \% 20 \mathrm{Tha} \% \mathrm{C} 3 \% \mathrm{ADs} \% 20 \mathrm{Teixeira} \% 20 \mathrm{de} \% 20$ Siqueir a.pdf Acesso 31/07/2013.

XAVIER, Clarissa Valadares e MAIA, Carlos Eduardo Santos. A diversidade dos carnavais no Brasil: sobre fantasias e abadás. In: ArtCultura, Uberlândia, v. 11, n. 19, p. 211-224, jul.-dez. 2009.

http://www.seer.ufu.br/index.php/artcultura/article/view/11284/7116. Acesso em 18/04/2014 
* Este artigo foi elaborado a partir de pesquisas realizadas por meio do Projeto Prócultura "A dimensão territorial das festas populares e do turismo: estudo comparativo do patrimônio imaterial em Goiás, Ceará e Sergipe" - MINC/CAPES (2009-2013)e reflexões preliminares do Projeto "Artes e saberes nas manifestações católicas populares" - FAPEG-005/2012.

Mary Anne Vieira Silva

Possui graduação em Geografia pela Universidade Federal do Ceará, mestrado em Geografia (Geografia Humana) pela Universidade de São Paulo e Doutorado em Geografia pela Universidade Federal de Goiás. Atualmente é professora Adjunta II da Universidade Estadual de Goiás.

Endereço: Rua Elias Gomes, Bl. 05 Ap. 104, Residencial Veneza, Vila Santa Maria de Nazaré, Anápolis-GO, CEP: 75 000-000

E-mail: Marymel2006@hotmail.com

\section{Maria Idelma Vieira D’Abadia}

Possui graduação em Geografia pela Faculdade de Ciências Econômicas de Anápolis, mestrado e doutorado em Geografia pela Universidade Federal de Goiás. Atualmente é professora efetiva da Universidade Estadual de Goiás, onde atua no Programa de Pesquisa e Pós-graduação Interdisciplinar Território e Expressões Culturais no Cerrado.

Endereço: R. Venezuela, Qd. 45 Lt. 19, Bairro Boa Vista, Anápolis-GO, CEP: 75083-360 E-mail: midabadia@bol.com.br

Recebido para publicação em maio de 2014 Aprovado para publicação em novembro de 2014 